\title{
HUBUNGAN SENAM HAMIL DENGAN KEMAJUAN PERSALINAN
}

\author{
Ika Putri Damayanti \\ STIkes Hang Tuah Pekanbaru
}

\begin{abstract}
ABSRTACT
Gymnastics Pregnant very important performed for birthing. In the face of labor generally mothers beset by anxiety and panic. This makes the muscles the way of birth and beyond hindering the smooth process in birth. Through various exercises and explanations of expected mothers more confidence and not to panic in the process of childbirth. Based on a preliminary survey conducted by researchers with the method of interview on the birthing mother 7 people, $4(57,15)$ mother said never follow gymnastics pregnant and 42.8 percent), three (mother says never follow gymnastics is pregnant. The purpose of this research is to know the relation of labor advances against pregnant gymnastics in Bidan Praktik Mandiri.

This research method using this type of quantitative research and cross sectional design. The research was held at the BPM on 02 Februai until 31 March 2019. The population in this research is the whole birthing mother Fatmawati and BPM in the sample retrieved as many as 34 respondents, with sampling purposive sampling basis IE. Data capture using primary data with menggunakanlembar cheklist, data processing done on computerization and data analysis done by Univariate and bivariat. Univariate results obtained most respondents did gymnastics get pregnant as many as 18 people $(52,8 \%)$ and progress of labor as much as 21 people (61.8 percent). While the analysis of the results obtained there bivariat relationship that may include the relationship between gymnastic pregnant with progression of labor-value value $=0.006 \mathrm{p} .<0.05$. Expected to health workers can provide information about the factors that relate to the advancement of labor gymnastics such as pregnant.
\end{abstract}

Keywords: Gymnastics is pregnant, the progress of delivery

\section{INTISARI}

Senam hamil sangat penting dilakukan untuk proses persalinan. Saat menghadapi persalinan umumnya ibu-ibu dilanda rasa cemas dan panik. Hal ini yang membuat otot-otot dijalan lahir dan sekitarnya menghambat kelancaran proses persalinan. Lewat berbagai latihan dan penjelasan diharapkan ibu lebih percaya diri dan tidak panik dalam proses persalinan. Berdasarkan survey pendahuluan yang dilakukan oleh peneliti dengan metode wawancara pada 7 orang ibu bersalin, 4 $(57,15)$ ibu mengatakan pernah mengikuti senam hamil dan $3(42,8 \%)$ ibu mengatakan tidak pernah mengikuti senam hamil. Tujuan penelitian ini adalah untuk mengetahui hubungan senam hamil terhadap kemajuan persalinan di Bidan Praktik Mandiri.

Metode penelitian ini menggunakan jenis penelitian kuantitatif dan desain cross sectional. Penelitian ini diadakan di BPM pada tanggal 02 Februai hingga 31 Maret tahun 2019. Populasi dalam penelitian ini adalah seluruh ibu bersalin di Bidan Praktik Mandiri dan sampel diperoleh sebanyak 34 responden, dengan teknik sampling yaitu secara purposive sampling. Pengambilan data menggunakan data primer dengan menggunakan lembar cheklist, pengolahan data dilakukan secara komputerisasi dan analisa data dilakukan dengan cara univariat dan bivariat. Hasil penelitian univariat diperoleh sebagian besar responden melakukan senam hamil sebanyak 18 orang $(52,8 \%)$ dan mengalami kemajuan persalinan sebanyak 21 orang $(61,8 \%)$. Sedangkan analisa bivariat diperoleh hasil terdapat hubungan yang siginifikan antara hubungan antara senam hamil dengan kemajuan persalinan dengan nilai p.value $=0,006<0,05$. Diharapkan kepada tenaga kesehatan dapat memberikan informasi tentang faktor-faktor yang berhubungan dengan kemajuan persalinan seperti senam hamil.

Kata Kunci : Senam hamil, Kemajuan Persalinan 


\section{PENDAHULUAN}

Senam hamil adalah terapi latihan gerak untuk mempersiapkan ibu hamil, secara fisik atau mental, pada persalinan cepat, aman dan sepontan. Ibu hamil dianjurkan untuk melakuna senam hamil bila kandungan sudah mencapai usia 6 bulan keatas (Widianti, 2010).

Kemajuan persalinan adalah tahapan proses dalam persalinan yang dapat di ukur menggunakan centimeter dengan seberapa lebar leher rahim sudah meluas atau barangkali dengan jumlah jari(satu jari sama dengan $1 \mathrm{~cm}$ ). Dilatasi biasanya diukur dari 1-10 $\mathrm{cm}$. Bila leher rahim dikatakan telah membuka secara penuh berarti pembukaan leher rahim telah bergaris tengah kira-kira $10 \mathrm{~cm}$. Ini adalah akhir dari tahap pertama persalinan, meskipun demikian dalam prakteknya tahap pertama secara berangsur-angsur dan pelan sering kali langsung masuk ke tahap kedua tanpa penghentian (Stoppard,2008).

Fungsi Senam hamil dengan mengacu pada sasaran utama senam hamil yaitu menyamankan kehamilan dengan mempermudah persalinan, makan program senam hamil ditujukan untuk: meningkatkan kebugaran tubuh secara keseluruhan, menguatkan dan mengencangkan otot-otot tertentu terutama otot-otot yang berperan untuk persalinan dan mempertahankan postur, meningkatkan relaksasi tubuh terutama otot dasar panggul yang berperan besar pada proses persalinan, melatih teknik pernafasan, yang sangat dibutuhkan untuk mengatasi rasa nyeri misalnya kala I maupun kala II (Widianti, 2010).

Ada beberapa faktor yang mempengaruhi kemajuan proses persalinan yaitu power (kekuatan ibu), passage (jalan lahir), passanger (kondisi janin), penolong dan psikologi dari ibu (Kuswanti,2014).

Saat menghadapi persalinan umumnya ibu-ibu dilanda rasa cemas dan panik. Hal ini yang membuat otot-otot dijalan lahir dan sekitarnya menghambat kelancaran proses persalinan. Lewat berbagai latihan dan penjelasan diharapkan ibu lebih percaya diri dan tidak panik dalam proses persalinan (Proverawati, 2010)

Berdasarkan survay pendahuluan yang dilakukan oleh peneliti dengan metode wawancara pada 7 orang ibu bersalin, $4(57,15)$ ibu mengatakan pernah mengikuti senam hamil dan 3 $(42,8 \%)$ ibu mengatakan tidak pernah mengikuti senam hamil. Ternyata ibu yang melakukan senam hamil dengan benar dapat menjalankan persalinan dengan lancar, cepat dan kemajuan persalinannya tidak terganggu.

Berdasarkan data diatas penulis tertarik untuk mengetahui "Hubungan 
Senam Hamil Dengan Kemajuan

Persalinan Di Rumah Bersalin Fatmawati

Pekanbaru Tahun 2019".

Tujuan penelitian ini adalah untuk menyetahui hubungan senam hamil terhadap kemajuan persalinan di Bidan Praktik Mandiri Tahun 2019.

\section{METODE PENELITIAN}

Metode penelitian ini menggunakan jenis penelitian kuantitatif dan desain cross sectional. Penelitian ini diadakan di BPM pada tanggal 02 Februai hingga 31 Maret tahun 2019. Populasi dalam penelitian ini adalah seluruh ibu bersalin di Bidan Praktik Mandiri dan sampel diperoleh sebanyak 34 responden, dengan teknik sampling yaitu secara purposive sampling. Pengambilan data menggunakan data primer dengan menggunakanlembar cheklist, pengolahan data dilakukan secara komputerisasi dan analisa data dilakukan dengan cara univariat dan bivariat.

\section{HASIL PENELITIAN}

Hasil penelitian ini disajikan secara dua analisa yang berbeda yaitu:

\section{Univariat}

\begin{tabular}{llll}
\hline No. & Kategori & Jumlah & $\mathbf{\%}$ \\
\hline 1. & Senam Hamil & & \\
& 1. Ya & $\mathbf{1 8}$ & $\mathbf{5 2 , 8}$ \\
& 2. Tidak & $\mathbf{1 6}$ & $\mathbf{4 7 , 1}$ \\
\hline Total & $\mathbf{3 4}$ & $\mathbf{1 0 0}$ \\
\hline 2. & Kemajuan & & \\
& Persalinan & $\mathbf{2 1}$ & $\mathbf{6 1 , 8}$ \\
& 1. Ya & $\mathbf{1 3}$ & $\mathbf{3 8 , 2}$ \\
& 2. Tidak & & \\
\hline Total & & $\mathbf{3 4}$ & $\mathbf{1 0 0}$ \\
\hline
\end{tabular}

Berdasarkan tabel 2 diketahui bahwa sebagian besar responden melakukan senam hamil sebanyak 18 responden $(52,8 \%)$ dan yang mengalami kemajuan persalinan sebanyak 21 responden $(61,8 \%)$.

\section{Bivariat}

\begin{tabular}{llllll}
\hline $\begin{array}{l}\text { Senam } \\
\text { hamil }\end{array}$ & \multicolumn{6}{l}{ Kemajuan Persalinan } & $\begin{array}{l}\mathbf{P} \\
\text { value }\end{array}$ & $\begin{array}{l}\text { OR } \\
(95 \% \text { CI })\end{array}$ \\
\cline { 2 - 4 } & Ya & Tidak & Total & \\
\hline Ya & 15 & 3 & 18 & 0,006 & 8,333 \\
\hline Tidak & 6 & 10 & 16 & & $(\mathrm{CI}: 1,82$ \\
\hline Total & 21 & 13 & 34 & & $-41,288)$ \\
\hline
\end{tabular}

Dari tabel 3 diketahui dari 18 responden yang melakukan senam hamil didapat sebanyak 15 responden $(44,1 \%)$ mengalami kemajuan saat persalinan dan 3 responden $(8,8 \%)$ tidak mengalami kemajuan persalinan. Sedangkan dari 16 responden yang tidak melakukan senam hamil didapat sebanyak 6 responden $(17,6 \%)$ mengalami kemajuan saat persalinan dan 10 responden $(29,4 \%)$ 
tidak mengalami kemajuan. Hasil uji chi square diperoleh $p_{\text {value }}$ yaitu $0,006<0,05$ artinya bahwa terdapat hubungan antara senam hamil dengan kemajuan persalinan. Analisis keeratan hubungan dua variabel didapatkan nilai Odss Ratio $(\mathrm{OR})=8,333 \quad(\mathrm{CI}: 1,82-41,288)$ yang artinya responden yang tidak melakukan senam hamil mempunyai peluang 8 kali berisiko mengalami persalinan tidak maju.

\section{PEMBAHASAN}

\section{Hubungan Senam Hamil Dengan Kemajuan Persalinan Di Bidan Praktik Mandiri Tahun 2019}

Berdasarkan hasil kolerasi diperoleh hasil univariat yaitu dari 18 orang $(52,9 \%)$ ibu hamil yang melakukan senam hamil didapat sebanyak 15 orang $(44,1 \%)$ mengalami kemajuan saat persalinan dan 3 orang $(8,8 \%)$ tidak mengalami kemajuan persalinan. Sedangkan dari 16 orang ibu yang tidak melakukan senam hamil didapat sebanyak 6 orang $(17,6 \%)$ mengalami kemajuan saat persalinan dan 10 orang $(29,4 \%)$ tidak mengalami kemajuan. Sedangkan hasil uji chi square diperoleh $\mathrm{P}_{\text {value }}$ yaitu $0,006<0,05$ artinya bahwa terdapat hubungan antara senam hamil dengan kemajuan persalinan, dan nilai Odss Ratio $(\mathrm{OR})=8,333$ (CI:1,82-
41,288) yang artinya ibu yang tidak melakukan senam hamil mempunyai peluang 8 kali berisiko mengalami persalinan tidak maju.

Fungsi Senam hamil dengan mengacu pada sasaran utama senam hamil yaitu menyamankan kehamilan dengan mempermudah persalinan, maka program senam hamil ditujukan untuk: meningkatkan kebugaran tubuh secara keseluruhan, menguatkan dan mengencangkan otot-otot tertentu terutama otot-otot yang berperan untuk persalinan dan mempertahankan postur, meningkatkan relaksasi tubuh terutama otot dasar panggul yang berperan besar pada proses persalinan, melatih teknik pernafasan, yang sangat dibutuhkan untuk mengatasi rasa nyeri misalnya kala I maupun kala II (Widianti, 2010). Saat menghadapi persalinan umumnya ibu-ibu dilanda rasa cemas dan panik. Hal ini yang membuat otot-otot dijalan lahir dan sekitarnya menghambat kelancaran proses persalinan. Lewat berbagai latihan dan penjelasan diharapkan ibu lebih percaya diri dan tidak panik dalam proses persalinan (Proverawati, 2010).

Kehamilan adalah proses yang alamiah dan fisiologis yang dialami wanita. Umunya, setelah umur kehamilan 40 minggu jika tidak ada penyulit dan penyakit penyerta maka wanita hamil akan mengalami proses persalinan yaitu 
serangkaian proses yang berahir dengan pengeluaran hasil konsepsi. Untuk meningkatkan derajat kesehatan ibu, pemerintah mencanangkan program asuhan antenatal. Senam hamil dimulai setelah kehamilan 22 minggu dan minimal dilakukan selama 30-60 menit. Senam hamil bukan merupakan keharusan, namun dengan melakukan senam hamil akan memberikan banyak manfaat dalam proses persalinan (Datta,2008)

Pergerakan dan latihan dari senam kehamilan tidak saja menguntungkan sang ibu, tetapi juga sangat berpengaruh terhadap kesehatan bayi yang dikandungnya. Pada saat bayi mulai dapat bernafas sendiri, maka oksigen akan mengalir kepadanya melalui plasenta, yaitu dari aliran darah ibunya ke dalam aliran darah bayi yang dikandung. Senam kehamilan akan menambah jumlah oksigen dalam darah di seluruh tubuh sang ibu dan karena itu aliran oksigen kepada bayi melalui plasenta juga akan menjadi lancar (Sani; 2002).

Latihan senam hamil tidak dapat dikatakan sempurna bila penyajiannya tidak disusun secara teratur yaitu minimal satu kali dalam seminggu yang dimulai saat umur kehamilan 24 minggu. Dengan mengikuti senam hamil secara teratur dan intensif, wanita tersebut akan menjaga kesehatan tubuhnya dan janin yang dikandungnya secara optimal (Evariny; 2007).

Masih banyak ibu hamil yang meragukan apakah melakukan gerakan senam hamil aman untuk kehamilannya atau tidak. Kegiatan senam ringan, berjalan santai, juga berenang dapat membantu anda untuk menstimulasi kerja jantung dan otot-otot saat persalinan. Senam dan berenang membantu memanfaatkan oksigen dan meningkatkan sirkulasi darah, serta memperkuat otot perut dan bahu (Widianti, 2010).

Berdasarkan hasil penelitian Sri Wahyuni (2009), hasil penelitian diperoleh bahwa dari 15 ibu hamil yang mengikuti senam hamil ternyata $80 \%$ proses persalinanya normal, dean $20 \%$ proses persalinannya tidak normal, sedangkan 15 ibu hamil yang tidak mengikuti senam hamil $66,66 \%$ persalinannya tidak normal, dan 33,33\% proses persalinannya normal. Dan dapat disimpulkan bahwa terdapat Hubungan yang signifikan antara senam hamil dengan proses persalinan di RSIA Aisyiyah Klaten dengan nilai $\mathrm{p}=0,003<$ 0,05 .

Hasil penelitian ini didukung oleh penelitian yang dilakukan oleh Bernadita (2003), bahwa terdapat hubungan senam hamil dengan proses persalinan di klinik Hj Endang Tungkak Yogyakarta. Hasil 
penelitian ini sejalan dengan pendapat Muchtar(1998), bahwa senam hamil yang teratur dapat membantu proses persalinan berlangsung alami dan lancer.

Menurut hasil penelitian Elizawarda (2003) tetang Studi kasus kelola faktor resiko untuk pencegahan lama persalinan di Rumah Sakit Umum Dr Pirngadi Kota Medan menunjukkan adanya hubungan yang signifikasi antara senam hamil dengan kejadian lama persalinan.

Berdasarkan hasil penelitian dan teori diatas, peneliti berasumsi bahwa kemajuan persalinan dipengaruhi oleh faktor senam hamil. Akan tetapi ada beberapa ibu yang tidak melakukan senam hamil namun mengalami kemajuan persalinan hal ini disebabkan oleh karena faktor lain yaitu ibu mampu melakukan teknik pernapasan yang baik, sedangkan ibu yang melakukan senam hamil namun tidak mengalami kemajuan persalinan kemungkinan disebabkan oleh faktor ibu merupakan primigravida sehingga pengetahuannya kurang baik tentang teknik pernapasan yang baik.

\section{KESIMPULAN}

1. Dari 34 responden diperoleh hasil sebagian besar responden melakukan senam hamil sebanyak 18 orang $(52,8 \%)$

2. Dari 34 responden diperoleh hasil sebagian besar mengalami kemajuan persalinan sebanyak 21 orang $(61,8 \%)$.

3. Terdapat hubungan yang siginifikan antara hubungan antara senam hamil dengan kemajuan persalinan, hasil uji chi square diperoleh $p_{\text {value }}$ yaitu 0,006 $<0,05$ dan nilai Odss Ratio $(\mathrm{OR})=$ 8,333 (CI:1,82-41,288) yang artinya ibu yang tidak melakukan senam hamil mempunyai peluang 8 kali berisiko mengalami persalinan tidak maju

\section{SARAN}

1. Diharapkan kepada tenaga kesehatan dapat memberikan informasi tentang faktor-faktor yang berhubungan dengan kemajuan persalinan seperti senam hamil

2. Diharapkan pada institusi untuk lebih memperbanyak referensi diperpustakaan khususnya mengenai senam hamil dan kemajuan persalinan

\section{DAFTAR PUSTAKA}

Bagian Obstetri \& Ginekologi Fakultas Kedokteran Universitas Padjajaran Bandung, 1983. Obstetri Fisiologi. Percetakan Eleman. Bandung. 
Widianti Anggraini Tri, dkk, 2010. Senam Kesehatan. Medical Book. Yogyakarta.

Data Monika, 2008. Panduan praktis kehamilan dan Melahirkan. PT Bhuana Ilmu Populer.Jakarta.

Mochtar Rustam, 1998. Sinopsis Obstetri. Penerbit Buku Kedokteran EGC. Jakarta.

POGI IBI, Depkes 2008. Asuhan Persalinan Normal. Depkes, JNPKKR. Jakarta.

Prawiroharjo Sarwono, 2002. Ilmu Kebidanan. Yayasan Bina Pustaka. Jakarta Pusat.

Kuswanti Ina, 2014. Askeb II persalinan. Pustaka pelajar.Yogyakarta.

Sulistyawati Ari, 2010. Asuhan

Kebidanan Pada masa kehamilan. Salemba Medika. Jakarta.
Chapman Vicky, 2006. Asuhan Kebidanan Persalinan Dan Kelahiran. Penerbit Buku Kedokteran EGC. Jakarta.

Widdowson Rosalind, 2003. Yoga Untuk Kehamilan Senam Persiapan Melahirkan untuk Menghadapi Tubuh saat Kelahiran. Erlangga.

Ester Monika, 2007. Senam Hamil Dan Nifas Pedoman Praktis Bidan. Penerbit Buku Kedokteran EGC. Jakarta.

Suryono Ari Setiawan, 2011. Metodologi Penelitian Kebidanan. Nuha Medika. Yogyakarta.

Varney Helen, 1999. Buku Kebidanan. Penerbit Buku Kedokteran. Jakarta.

Yerniah,(2009).http//wordpress.co 2009/Hubungan-senam-hamildengan-proses-persalinan. 